\title{
Seleção de Plantas com Potencial para fitorremediação de TEBUTHIURON ${ }^{1}$
}

\author{
Plant Selection with Potential for Tebuthiuron Phytodecontamination
}

\author{
PIRES, F.R. ${ }^{2}$, SOUZA, C.M. ${ }^{3}$, SILVA, A.A. ${ }^{3}$, QUEIROZ, M.E.L.R. ${ }^{4}$, PROCÓPIO, S.O. ${ }^{2}$, SANTOS, \\ J.B. ${ }^{5}$, SANTOS, E.A. ${ }^{6}$ e CECON, P.R. ${ }^{7}$
}

\begin{abstract}
RESUMO - Este trabalho teve como objetivo selecionar espécies tolerantes ao tebuthiuron, visando utilizá-las em programas de fitorremediação de solos contaminados com esse herbicida. Foram avaliadas: Amaranthus hybridus, Crotalariajuncea, Chamaesyce hyssopifolia, C. hirta, Canavalia ensiformes, Helianthus annus, Pennisetum typhoides, Estizolobium aterrimum, Raphanus raphanistrum e Crotalaria incana. O experimento foi conduzido em casa de vegetação, em vasos contendo $3 \mathrm{dm}^{3}$ de solo de textura argilo-arenosa com $2,18 \mathrm{dag} \mathrm{kg}^{-1}$ de matéria orgânica. O experimento foi delineado em blocos ao acaso, com três repetições de tratamentos em fatorial $10 \times 4 \times 4$, os quais foram constituídos por 10 espécies, quatro doses de tebuthiuron $\left(0,0 ; 5,0 ; 1,0 ;\right.$ e $\left.2,0 \mathrm{~kg} \mathrm{ha}^{-1}\right)$, aplicadas em pré-emergência, e quatro épocas de avaliação (15, 30, 45 e 60 dias após a semeadura). Foram avaliadas a fitotoxicidade do herbicida, a altura de plantas e a massa de matéria seca da parte aérea, de raízes e do total da planta. Canavalia ensiformes e Pennisetum typhoides foram tolerantes ao tebuthiuron na dose de 0,5 $\mathrm{kg} \mathrm{ha}^{-1}$. Estizolobium aterrimum tolerou tebuthiuron até a dose de $1,0 \mathrm{~kg} \mathrm{ha}^{-1}$, apresentando fitotoxicidade menos acentuada e menor redução de altura de plantas e da massa de matéria seca da parte aérea, de raízes e do total da planta em relação ao tratamento testemunha.
\end{abstract}

Palavras-chave: seletividade, fitotoxicidade, descontaminação, adubos verdes, plantas daninhas.

\begin{abstract}
This study aimed to select tebuthiuron-tolerant plants to use them in phytoremediation programs in contaminated soils. The evaluated species were: Amaranthus hybridus, Crotalaria juncea, C. hyssopifolia, Chamaesyce hirta, Canavalia ensiformes, Helianthus annus, Pennisetum typhoides, Estizolobium aterrimum, Raphanus raphanistrum and Crotalaria incana. The experiment was carried out in a greenhouse, with

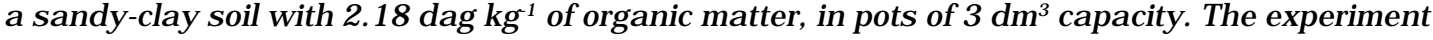
was arranged in a $10 \times 4 \times 4$ factorial scheme in a randomized block design with three replications. The treatments consisted of: 10 species, four tebuthiuron doses $\left(0.0 ; 0.5 ; 1.0\right.$ e $\left.2.0 \mathrm{~kg} \mathrm{ha}^{-1}\right)$ applied in pre-emergence, and four evaluation times (15, 30, 45, and 60 days after sowing). Phytotoxicity, plant height and, above-ground, root and total biomass dry matter were evaluated. Canavalia ensiformes and Pennisetum typhoides were tolerant to tebuthiuron at the dose of $0.5 \mathrm{~kg} \mathrm{ha}^{-1}$, and Estizolobium aterrimum up to the dose of $1.0 \mathrm{~kg} \mathrm{ha} \mathrm{h}^{-1}$, with the latter showing less phytotoxicity symptoms and a smaller reduction of plant height, above-ground, root, and total biomass dry matter, as compared to the control treatment.
\end{abstract}

Key words: selectivity, phytotoxicity, decontamination, green manure, weeds.

Recebido para publicação em 28.11.2002 e na forma revisada em 12.12.2003.

Doutorando do Dep. de Fitotecnia da Universidade Federal de Viçosa - UFV, Bolsista CNPq, 36571-000 Viçosa-MG; ${ }^{3}$ Prof. do Dep. de Fitotecnia da UFV; ${ }^{4}$ Prof. do Dep. de Química da UFV; ${ }^{5}$ Mestrando do Dep. de Fitotecnia da UFV; ${ }^{6}$ Acadêmico do Dep. de Agronomia da UFV; ${ }^{7}$ Prof. do Dep. de Informática da UFV.

Planta Daninha, Viçosa-MG, v.21, n.3, p.451-458, 2003 


\section{INTRODUÇÃO}

O desenvolvimento de moléculas herbicidas com longo efeito residual possibilitou tanto o controle efetivo de plantas daninhas por maior período de tempo como a redução do número de aplicações. No entanto, essa residualidade tem provocado fitotoxicidade em culturas sensíveis plantadas após a utilização desses herbicidas (carryover). Além disso, com o uso de herbicidas de longo residual no solo há maior probabilidade de ocorrência de lixiviação de suas moléculas originais ou de seus metabólitos para camadas mais profundas no perfil do solo, com a conseqüente contaminação do aqüífero subterrâneo.

Dentre os herbicidas que apresentam longo residual no solo destaca-se o tebuthiuron, $\mathrm{N}-\{5-$ (1,1-dimetiletil)-1,3,4-tiadiazol-2-il\}-n,n'dimetiluréia, recomendado para uso em préemergência na cultura da cana-de-açúcar. Sua persistência no solo pode variar de 11 a 14 meses (Blanco \& Oliveira, 1987), de 15 a 25 meses (Meyer \& Bovey, 1988) ou mesmo estender-se até 7,2 anos (Emmerich et al., 1984). O produto apresenta elevada mobilidade em solos com baixos teores de argila e de carbono orgânico, sendo, portanto, fonte potencial para contaminação dos aqüíferos, principalmente como resultado de aplicações seqüenciais ao longo dos anos, na mesma área (Cerdeira et al., 1999). Tanto o potencial de fitotoxicidade por longa residualidade como o de contaminação de aqüíferos podem ser amenizados pelo emprego de técnicas que acelerem a retirada desse composto do solo, promovendo sua descontaminação. Dentre essas técnicas destaca-se a fitorremediação.

A fitorremediação utiliza plantas como organismos descontaminantes de solos e água e pode ser usada em áreas contaminadas com substâncias orgânicas e inorgânicas (Cunningham et al., 1996).

A fitorremediação baseia-se na tolerância que algumas espécies exibem a determinados produtos. A tolerância pode ser resultante de processos como a translocação diferencial (maior ou menor) de compostos orgânicos para outros tecidos da planta, com subseqüente volatilização; a degradação parcial ou completa; e a transformação em compostos menos tóxicos, combinados e/ou ligados nos tecidos das plantas (Accioly \& Siqueira, 2000; Scramin et al., 2001). Em geral, a maioria dos compostos orgânicos passa por alguma transformação nas células das plantas antes de serem isolados em vacúolos ou ligarem-se a estruturas celulares insolúveis, como a lignina (Macek et al., 2000).

Na fitoestimulação, que é considerada uma forma de fitorremediação, ocorre a liberação de exsudatos radiculares e há o estímulo à atividade microbiana, que degrada o composto no solo, caracterizando, em algumas plantas, a aptidão rizosférica para a biorremediação de compostos tóxicos (Cunningham et al., 1996).

Diversos trabalhos relatam o efeito positivo da utilização de plantas na descontaminação do solo (Anderson \& Coats, 1995; Kruger et al., 1997; Hoagland et al., 1997). No Brasil, a pesquisa nessa área é ainda incipiente, não havendo relatos sobre o uso da fitorremediação de tebuthiuron.

A seleção de plantas que apresentam tolerância ao tebuthiuron é o primeiro passo na seleção de espécies potencialmente fitorremediadoras. Entretanto, deve-se evitar a utilização de espécies de difícil controle e, se possivel, selecionar aquelas que proporcionam outros benefícios ao solo, como é o caso das que são utilizadas como adubos verdes ou para cobertura do solo. Contudo, há poucas pesquisas sobre a tolerância dessas espécies a herbicidas. Silva \& Bueno (2000a) avaliaram a tolerância das leguminosas Pueraria phaseoloides, Desmodium ovalifolium, Mucuna aterrima e Mucuna cochinchinensis ao 2,4-DB em pós-emergência e ao alachlor, imazaquin e pendimenthalin, em pré-emergência, em cinco doses de cada herbicida. D. ovalifolium foi a espécie mais suscetível aos herbicidas nas doses usadas, exceto ao alachlor. M. aterrima foi tolerante ao alachlor, imazaquin e pendimenthalin, sendo suscetivel apenas ao 2,4-DB. P. phaseoloides e $M$. conchinchinensis foram suscetiveis ao pendimenthalin e 2,4-DB. Silva \& Bueno (2000b), ao utilizarem acifluorfen, bentazon e lactofen em pós-emergência e metribuzin em pré-emergência, observaram que $M$. aterrima apresentou sensibilidade moderada ao acifluorfen, boa tolerância ao bentazon e tolerância moderada ao lactofen e ao metribuzin. 
Entre os poucos relatos sobre a seletividade de tebuthiuron a adubos verdes pode-se citar o de Dal Piccolo \& Christoffoleti (1985). Os autores constataram inibição no crescimento da Crotalaria juncea até 13 meses após a aplicação do herbicida.

Não obstante os resultados apresentados, a seletividade dos herbicidas às culturas varia em função do modo de aplicação, do estádio da planta no momento da aplicação e da arquitetura foliar, da dose utilizada, das condições climáticas, da adição de surfatantes, da variedade ou do cultivar (Almeida, 1986; Azania et al., 2001; Cobucci \& Portela, 2001) e de outros fatores.

Este trabalho teve como objetivo selecionar espécies vegetais tolerantes ao tebuthiuron, visando utilizá-las em programas de fitorremediação.

\section{MATERIAL E MÉTODOS}

Foram escolhidas 10 espécies de plantas com provável potencial para tolerarem o herbicida tebuthiuron e serem empregadas na fitorremediação do solo. A seleção de espécies de plantas daninhas foi feita com base em informações relatadas em Lorenzi (2000). Também foram selecionadas espécies que apresentam valor agrícola/econômico, visando seu aproveitamento na agricultura. Foram incluídas leguminosas, crucíferas, gramíneas, amarantáceas e compostas, sendo elas: caruru-roxo (Amaranthus hybridus), crotaláriajuncea (Crotalaria juncea), erva-andorinha (Chamaesyce hyssopifolia), erva-de-santa-luzia (Chamaesye hirta), feijão-guandu (Canavalia ensiformes), girassol (Helianthus annus), milheto (Pennisetum typhoides), mucuna-preta (Estizolobium aterrimum), nabiça (Raphanus raphanistrum) e xiquexique (Crotalaria incana).

O experimento foi conduzido em casa de vegetação do Departamento de Fitotecnia da Universidade Federal de Viçosa. Como substrato, utilizou-se material de solo classificado como Argissolo Vermelho-Amarelo, de textura argilo-arenosa, coletado sob vegetação de mata secundária, na profundidade de $0-20 \mathrm{~cm}$, e peneirado em malha de $0,004 \mathrm{~m}$. Sua caracterização física e química está apresentada na Tabela 1.

O experimento foi delineado em blocos ao acaso, com três repetições de tratamentos em fatorial $10 \times 4 \times 4$. Estes foram constituídos por 10 espécies vegetais, quatro doses de tebuthiuron e quatro épocas de avaliação, totalizando 160 tratamentos. A unidade experimental foi vaso de polietileno, contendo $3 \mathrm{dm}^{3}$ de solo. Após o enchimento dos vasos, procedeu-se, no dia 18.4.2002, à aplicação de tebuthiuron, em pré-emergência, nas doses deHO,0; 0,5; 1,$0 ;$ e $2,0 \mathrm{~kg} \mathrm{ha}^{-1}$ do produto comercial (Combine $500 \mathrm{SC}$ ), equivalendo a 0 , $1 / 2,1$ e 2 vezes a dose comercial ( $\left.1 \mathrm{~kg} \mathrm{ha}^{-1}\right)$, simulando diferentes níveis de contaminação do solo. O tebuthiuron foi aplicado com equipamento costal pressurizado com gás carbônico $\left(\mathrm{CO}_{2}\right)$ e barra com duas pontas de jato plano 110:03 da marca Jacto, espaçadas de 0,50 m, cobrindo a largura de $1 \mathrm{~m}$. O volume de aplicação foi de $260 \mathrm{~L} \mathrm{ha}^{-1}$.

A semeadura foi feita no dia seguinte à aplicação de tebuthiuron. Depois da aplicação dos tratamentos, os vasos foram irrigados sempre que necessário para manter a umidade

Tabela 1 - Composição físico-química do solo ${ }^{1 /}$

\begin{tabular}{|c|c|c|c|c|c|c|c|c|c|c|}
\hline \multicolumn{11}{|c|}{ Análise Granulométrica $\left(\mathrm{dag} \mathrm{kg}^{-1}\right)$} \\
\hline \multicolumn{2}{|c|}{ Argila } & \multicolumn{2}{|c|}{ Silte } & \multicolumn{2}{|c|}{ Areia Fina } & \multicolumn{2}{|c|}{ Areia Grossa } & \multicolumn{3}{|c|}{ Classificação Textural } \\
\hline \multicolumn{2}{|c|}{39} & \multicolumn{2}{|c|}{11} & \multicolumn{2}{|c|}{17} & \multicolumn{2}{|l|}{33} & \multicolumn{3}{|c|}{ Argilo-arenosa } \\
\hline \multicolumn{11}{|c|}{ Análise Química } \\
\hline $\mathrm{pH}$ & $\mathrm{P}$ & $\mathrm{K}^{+}$ & $\mathrm{Al}^{3+}$ & $\mathrm{Ca}^{2+}$ & $\mathrm{Mg}^{2+}$ & $\mathrm{H}+\mathrm{Al}$ & CTC total & $\mathrm{V}$ & $\mathrm{m}$ & $\mathrm{MO}$ \\
\hline $\mathrm{H}_{2} \mathrm{O}$ & \multicolumn{2}{|c|}{$\left(\mathrm{mg} \mathrm{dm}^{-3}\right)$} & \multicolumn{5}{|c|}{$\left(\mathrm{cmol}_{\mathrm{c}} \mathrm{dm}^{-3}\right)$} & \multicolumn{2}{|c|}{$(\%)$} & $\left(\right.$ dag $\left.\mathrm{kg}^{-1}\right)$ \\
\hline 5,8 & 1,4 & 123 & 0,0 & 3,8 & 1,4 & 4,3 & 9,81 & 56 & 0 & 2,18 \\
\hline
\end{tabular}

${ }^{1 /}$ Análises realizadas nos Laboratórios de Análises Físicas e Químicas de Solo do Departamento de Solos da UFV, segundo a metodologia da Empresa Brasileira de Pesquisa Agropecuária-EMBRAPA (1997). 
do solo em torno de $80 \%$ da capacidade de campo. Para determinar a seletividade de tebuthiuron às espécies, foram avaliadas, aos $15,30,45$ e 60 dias após a semeadura (DAS), a toxicidade do produto às plantas, a altura de plantas e, aos 60 DAS, também a massa de matéria seca da parte aérea, das raízes e do total da planta.

Na avaliação da fitotoxicidade atribuíramse notas de 0 a 100, de acordo com os sintomas de intoxicação na parte aérea das plantas, em que 0 representa ausência de sintomas e 100 a morte da planta. A altura das plantas foi medida do colo até o meristema apical nas dicotiledôneas e até a extremidade da última folha nas demais espécies. Para determinar a massa de matéria seca da parte aérea, das raízes e do total da planta (parte aérea + raízes), o material colhido foi seco em estufa de circulação de ar forçada (70 $\left.\pm 2{ }^{\circ} \mathrm{C}\right)$ por 72 horas.

Como os dados não atenderam às pressuposições de normalidade e homogeneidade para a realização da análise de variância, fez-se a análise descritiva dos dados.

\section{RESULTADOS E DISCUSSÃO}

Analisando os resultados apresentados na Tabela 2, observa-se que a mucuna-preta foi a espécie que apresentou maior tolerância ao tebuthiuron, com sintomas de toxicidade menos acentuados e menor redução de altura de plantas e de massa de matéria seca da parte aérea em relação ao tratamento testemunha. Resultados semelhantes foram obtidos por Silva \& Bueno (2000 a, b). A mucuna-preta também apresentou a menor redução de massa de matéria seca de raízes e do total em relação à testemunha. Esse resultado foi observado até a dose de $1,0 \mathrm{~kg} \mathrm{ha}^{-1}$ (dose comercial recomendada). No entanto, quando se utilizou a dose de 2,0 kg ha-1, nenhuma das espécies sobreviveu ao tebuthiuron. O feijão-guandu e o milheto exibiram tolerância à dose de $0,5 \mathrm{~kg} \mathrm{ha}^{-1}$. Na dose de $1,0 \mathrm{~kg} \mathrm{ha}^{-1}$ os sintomas de toxicidade foram mais acentuados e as reduções de altura e de massa de matéria seca foram pronunciadas. $\mathrm{O}$ amplo espectro de ação do tebuthiuron e seu longo efeito residual (Dal Piccolo \& Christoffoleti, 1985; Blanco \& Oliveira, 1986) corroboram a dificuldade de identificar espécies que lhe sejam tolerantes e que, concomitantemente, apresentem interesse agronômico, características estas desejáveis numa planta fitorremediadora.

A evolução dos sintomas de toxicidade causada pelas três doses do herbicida, nas dez espécies testadas, dos 15 aos 60 dias, está representada na Figura 1. Na dose de $0,5 \mathrm{~kg} \mathrm{ha}^{-1}$ (metade da dose comercial recomendada) observa-se que, desde a primeira avaliação (15 DAS), erva-andorinha, crotalária-juncea, nabiça, caruru-roxo, xiquexique e erva-desanta-luzia apresentaram sintomas de toxicidade superiores a $80 \%$ em relação à testemunha sem herbicida. Nessa dose, por ocasião da última avaliação (60 DAS), houve morte das plantas, exceto de nabiça, na qual se observou fitotoxicidade de $84 \%$. Milheto e girassol apresentaram fitotoxicidade semelhante até os 15 DAS, porém o primeiro recuperou-se, chegando à ultima avaliação com cerca de $43 \%$ de fitotoxicidade. O girassol, por sua vez, mostrouse mais sensivel, com $60 \%$ de fitotoxicidade aos 60 DAS.

As espécies que apresentaram maior tolerância ao tebuthiuron na dose de $0,5 \mathrm{~kg} \mathrm{ha}^{-1}$ foram a mucuna-preta, sem fitotoxicidade, e o feijão-guandu, com $20 \%$ de fitotoxicidade até os 60 DAS. Na dose de $1,0 \mathrm{~kg} \mathrm{ha}^{-1}$, a evolução dos sintomas de fitotoxicidade foi semelhante para a maioria das espécies testadas. O milheto, com cerca de $76 \%$, e a mucuna-preta, com $20 \%$, foram as únicas espécies que não foram totalmente controladas com a aplicação da dose de $1,0 \mathrm{~kg} \mathrm{ha}^{-1}$. Novamente, a mucuna-preta foi a espécie que exibiu maior tolerância ao tebuthiuron, contrariando a informação de Rodrigues \& Almeida (1998), os quais afirmam que normalmente as leguminosas são muito suscetiveis ao tebuthiuron.

Quando foram aplicados 2,0 $\mathrm{kg} \mathrm{ha}^{-1} \mathrm{de}$ tebuthiuron (duas vezes a dose comercial recomendada para solos de textura argilosa), nenhuma espécie sobreviveu ao herbicida até 60 DAS. A mucuna-preta até os 15 DAS apresentou fitotoxicidade leve; no entanto, até a avaliação seguinte (30 DAS), houve evolução dos sintomas para fitotoxicidade de $90 \%$, evidenciando maior ação herbicida entre 15 e 30 dias após a aplicação, para essa espécie. Contudo, as plantas de oito das dez espécies morreram aos 15 DAS, evidenciando a alta suscetibilidade delas a essa dose do herbicida. 
Tabela 2 - Fitotoxicidade e redução da altura de plantas e da biomassa de matéria seca da parte aérea aos 60 DAS ${ }^{1}$. Porcentagem em relação ao tratamento testemunha

\begin{tabular}{|c|c|c|c|c|c|c|c|c|}
\hline \multirow{3}{*}{ Espécie } & \multicolumn{8}{|c|}{ Tebuthiuron $\left(\mathrm{kg} \mathrm{ha}^{-1}\right)$} \\
\hline & \multicolumn{2}{|c|}{0,0} & \multicolumn{2}{|c|}{0,5} & \multicolumn{2}{|c|}{1,0} & \multicolumn{2}{|c|}{2,0} \\
\hline & $\mathrm{M}^{2 /}$ & $\mathrm{S}^{-3 /}$ & $\mathrm{M}$ & $\mathrm{S}$ & $\mathrm{M}$ & $\mathrm{S}$ & $\mathrm{M}$ & $\mathrm{S}$ \\
\hline \multicolumn{9}{|c|}{ Fitotoxicidade } \\
\hline Caruru-roxo & 0,0 & 0,0 & 99 & 1,15 & 100 & 0,0 & 100 & $\overline{0,0}$ \\
\hline Crotalária-juncea & 0,0 & 0,0 & 100 & 0,0 & 100 & 0,0 & 100 & 0,0 \\
\hline Erva-andorinha & 0,0 & 0,0 & 99 & 1,15 & 100 & 0,0 & 100 & 0,0 \\
\hline Erva-de-santa-luzia & 0,0 & 0,0 & 73 & 30 & 91 & 14 & 100 & 0,0 \\
\hline Feijão-guandu & 0,0 & 0,0 & 20 & 35 & 100 & 0,0 & 100 & 0,0 \\
\hline Girassol & 0,0 & 0,0 & 60 & 40 & 100 & 0,0 & 100 & 0,0 \\
\hline Milheto & 0,0 & 0,0 & 43 & 21 & 76 & 24 & 100 & 0,0 \\
\hline Mucuna-preta & 0,0 & 0,0 & 0,0 & 0,0 & 20 & 17 & 100 & 0,0 \\
\hline Nabiça & 0,0 & 0,0 & 83 & 29 & 100 & 0,0 & 100 & 0,0 \\
\hline Xiquexique & 0,0 & 0,0 & 100 & 0,0 & 100 & 0,0 & 100 & 0,0 \\
\hline \multicolumn{9}{|c|}{ Altura de Plantas } \\
\hline Caruru-roxo & 100 & 1,0 & 94 & 2,0 & 100 & 0,0 & 100 & 0,0 \\
\hline Crotalária-juncea & 100 & 15 & 100 & 0,0 & 100 & 0,0 & 100 & 0,0 \\
\hline Erva-andorinha & 100 & 0,3 & 100 & 0,0 & 100 & 0,0 & 100 & 0,0 \\
\hline Erva-de-santa-luzia & 100 & 0,4 & 81 & 0,9 & 94 & 0,2 & 100 & 0,0 \\
\hline Feijão-guandu & 100 & 5,1 & 3 & 3,8 & 100 & 0,0 & 100 & 0,0 \\
\hline Girassol & 100 & 1,5 & 56 & 23 & 100 & 0,0 & 100 & 0,0 \\
\hline Milheto & 100 & 27 & 18 & 19 & 42 & 13 & 100 & 0,0 \\
\hline Mucuna-preta & 100 & 44 & 28 & 30 & 23 & 53 & 100 & 0,0 \\
\hline Nabiça & 100 & 8,7 & 48 & 43 & 100 & 0,0 & 100 & 0,0 \\
\hline Xiquexique & 100 & 3,5 & 100 & 0,0 & 100 & 0,0 & 100 & 0,0 \\
\hline \multicolumn{9}{|c|}{ Massa de Matéria Seca da Parte Aérea } \\
\hline Caruru-roxo & 100 & 0,9 & 97 & 0,01 & 100 & 0,0 & 100 & 0,0 \\
\hline Crotalária-juncea & 100 & 0,5 & 100 & 0,0 & 100 & 0,0 & 100 & 0,0 \\
\hline Erva-andorinha & 100 & 0,3 & 100 & 0,0 & 100 & 0,0 & 100 & 0,0 \\
\hline Erva-de-santa-luzia & 100 & 0,4 & 81 & 0,9 & 94 & 0,2 & 100 & 0,0 \\
\hline Feijão-guandu & 100 & 1,2 & 43 & 0,9 & 100 & 0,0 & 100 & 0,0 \\
\hline Girassol & 100 & 1,4 & 68 & 3,1 & 100 & 0,0 & 100 & 0,0 \\
\hline Milheto & 100 & 2,6 & 22 & 2,4 & 80 & 1,0 & 100 & 0,0 \\
\hline Mucuna-preta & 100 & 2,6 & 50 & 2,3 & 13 & 1,0 & 100 & 0,0 \\
\hline Nabiça & 100 & 1,3 & 80 & 2,6 & 100 & 0,0 & 100 & 0,0 \\
\hline Xiquexique & 100 & 0,8 & 100 & 0,0 & 100 & 0,0 & 100 & 0,0 \\
\hline \multicolumn{9}{|c|}{ Massa de Matéria Seca de Raízes } \\
\hline Caruru-roxo & 100 & 3,4 & 69 & 1,7 & 100 & 0,0 & 100 & 0,0 \\
\hline Crotalária-juncea & 100 & 0,5 & 100 & 0,0 & 100 & 0,0 & 100 & 0,0 \\
\hline Erva-andorinha & 100 & 0,7 & +8 & 2,3 & 100 & 0,0 & 100 & 0,0 \\
\hline Erva-de-santa-luzia & 100 & 0,9 & 76 & 1,2 & 93 & 0,2 & 100 & 0,0 \\
\hline Feijão-guandu & 100 & 2,0 & 47 & 0,2 & 100 & 0,0 & 100 & 0,0 \\
\hline Girassol & 100 & 2,5 & 95 & 0,3 & 100 & 0,0 & 100 & 0,0 \\
\hline Milheto & 100 & 2,5 & 29 & 1,2 & 80 & 1,1 & 100 & 0,0 \\
\hline Mucuna-preta & 100 & 2,1 & +33 & 1,0 & 29 & 0,3 & 100 & 0,0 \\
\hline Nabiça & 100 & 3,4 & 79 & 1,9 & 100 & 0,0 & 100 & 0,0 \\
\hline Xiquexique & 100 & 0,4 & 100 & 0,0 & 100 & 0,0 & 100 & 0,0 \\
\hline \multicolumn{9}{|c|}{ Massa de Matéria Seca Total } \\
\hline Caruru-roxo & 100 & 4,1 & 83 & 1,7 & 100 & 0,0 & 100 & 0,0 \\
\hline Crotalária-juncea & 100 & 0,7 & 100 & 0,0 & 100 & 0,0 & 100 & 0,0 \\
\hline Erva-andorinha & 100 & 1,0 & 35 & 2,3 & 100 & 0,0 & 100 & 0,0 \\
\hline Erva-de-santa-luzia & 100 & 0,5 & 78 & 2,1 & 93 & 0,5 & 100 & 0,0 \\
\hline Feijão-guandu & 100 & 3,2 & 18 & 1,2 & 100 & 0,0 & 100 & 0,0 \\
\hline Girassol & 100 & 3,7 & 77 & 3,0 & 100 & 0,0 & 100 & 0,0 \\
\hline Milheto & 100 & 5,1 & 26 & 3,5 & 80 & 2,3 & 100 & 0,0 \\
\hline Mucuna-preta & 100 & 4,7 & +44 & 3,3 & 19 & 1,2 & 100 & 0,0 \\
\hline Nabiça & 100 & 2,9 & 80 & 4,5 & 100 & 0,0 & 100 & 0,0 \\
\hline Xiquexique & 100 & 1,0 & 100 & 0,0 & 100 & 0,0 & 100 & 0,0 \\
\hline
\end{tabular}

${ }^{1 /}$ Dias após a semeadura. ${ }^{2 /}$ Média de três repetições. ${ }^{3 /}$ Desvio-padrão. 
Dose de 0,5 kg ha ${ }^{-1}$

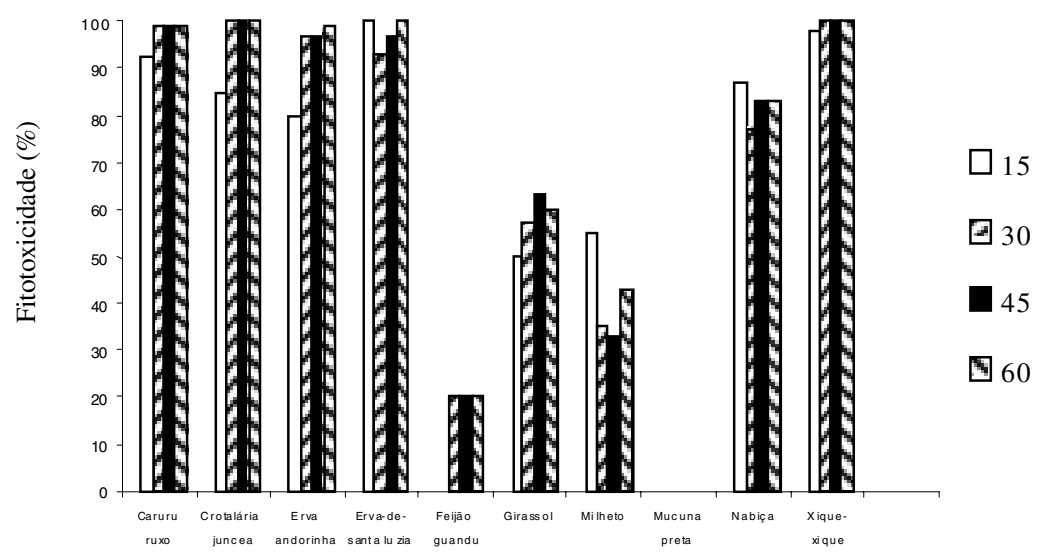

Dose de $1,0 \mathrm{~kg} \mathrm{ha}^{-1}$

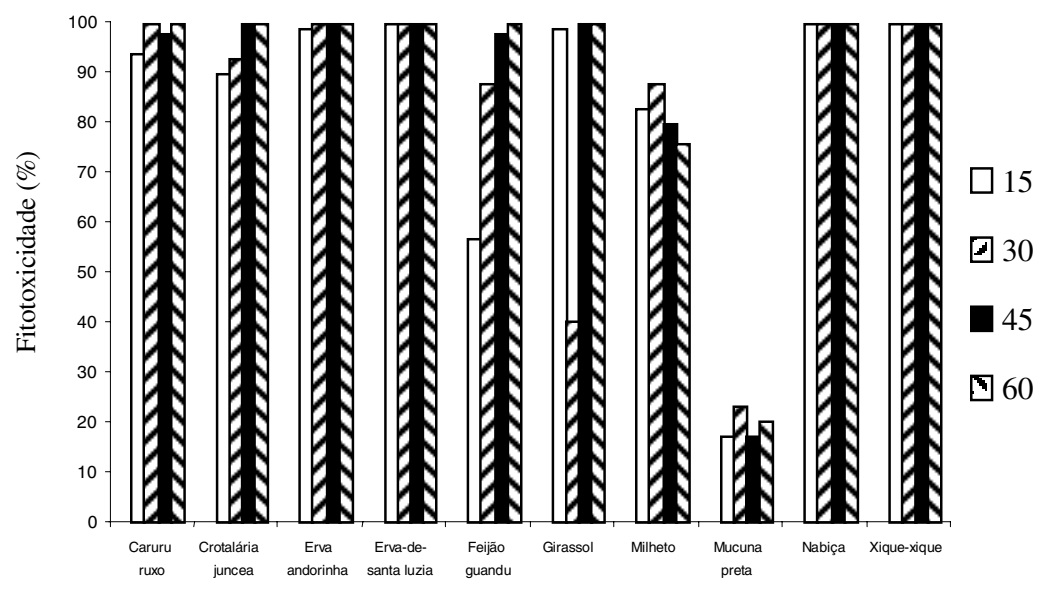

Dose de 2,0 kg ha ${ }^{-1}$

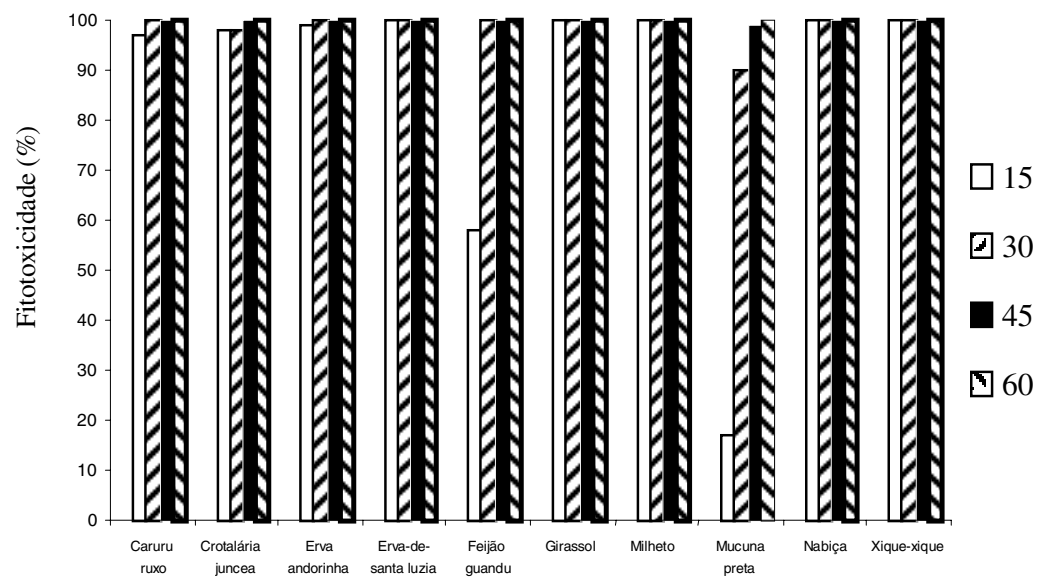

Figura 1 - Fitotoxicidade do tebuthiuron a dez espécies vegetais após a sua aplicação. Avaliações realizadas aos 15, 30, 45 e 60 dias após a semeadura. 


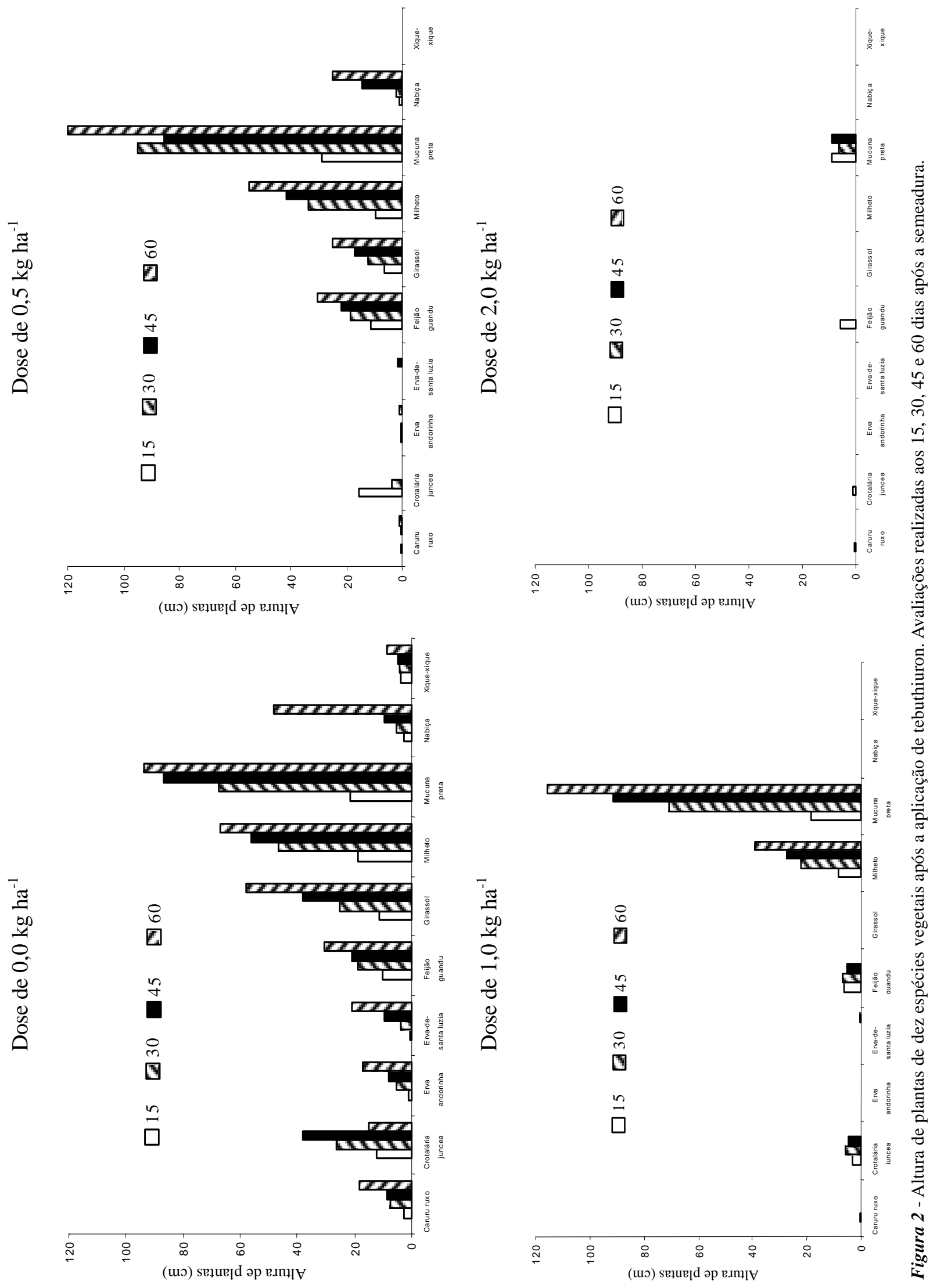

Planta Daninha, Viçosa-MG, v.21, n.3, p.451-458, 2003 
Houve redução progressiva da altura das plantas com o aumento das doses de tebuthiuron (Figura 2), refletindo seu efeito na arquitetura da planta. $\mathrm{Na}$ dose de $0,5 \mathrm{~kg} \mathrm{ha}^{-1}$, apenas a mucuna-preta e o feijão-guandu não tiveram sua altura reduzida em relação à testemunha. Na dose de $1,0 \mathrm{~kg} \mathrm{ha}^{-1}$, apenas a mucuna-preta não apresentou redução representativa na altura das plantas; na dose de $2,0 \mathrm{~kg} \mathrm{ha}^{-1}$, aos 15 DAS, praticamente todas as espécies apresentaram altura de plantas próxima a zero (mortas).

Nas condições ambientais em que o experimento foi conduzido, pode-se concluir que, dentre as espécies avaliadas, o feijão-guandu e o milheto exibiram alguma tolerância ao tebuthiuron, na dose de $0,5 \mathrm{~kg} \mathrm{ha}^{-1}$. A mucuna-preta apresentou maior tolerância ao tebuthiuron até a dose comercial (1,0 kg ha-1), com menores sintomas de fitotoxicidade e menor redução de altura de plantas e de massa de matéria seca da parte aérea, das raízes e do total em relação ao tratamento testemunha, indicando seu potencial de utilização para posteriores estudos de fitorremediação de tebuthiuron em solo.

\section{LITERATURA CITADA}

ACCIOLY, A. M. A.; SIQUEIRA, J. O. Contaminação química e biorremediação do solo. In: NOVAIS, R. F.; ALVAREZ V.; V. H.; SCHAEFER, C. E. G. R. Tópicos em ciência do solo. Viçosa: Sociedade Brasileira de Ciência do Solo, 2000. v. 1. p. 299-352.

ALMEIDA, J. C. V. Seletividade e sítios de absorção de sethoxydin em gramíneas e sua atividade no solo. 1986. 61 f. Dissertação (Mestrado em Fitotecnia) - Universidade Federal de Viçosa, Viçosa, 1986.

ANDERSON, T. A.; COATS, J. R. Screening rhizosphere soil samples for the ability to mineralize elevated concentrations of atrazine and metolachlor. J. Environ. Sci. Health, v. 30, p. 473-84, 1995.

AZANIA, C. A. M.; CASAGRANDE, A. A.; ROLIM, J. C. Seletividade de imazapic às soqueiras de cana-de-açúcar (Saccharum spp.). Planta Daninha, v. 19, p. 345-350, 2001.

BLANCO, J. G.; OLIVEIRA, D. A. Persistência de herbicidas em Latossolo Vermelho-Amarelo em cultura de cana-de-açúcar. Pesq. Agropec. Bras., v. 22, p. 681-687, 1987.

CERDEIRA, A. L. et al. Herbicide and nitrate residues in surface and groundwater from sugarcane area in Brazil. Boll. Chim. Farm., v. 138, n. 2, p. 131, 1999.

Planta Daninha, Viçosa-MG, v.21, n.3, p.451-458, 2003
COBUCCI, T.; PORTELA, C. Seletividade de herbicidas aplicados em diferentes estádios de desenvolvimento da cultura do arroz de terras altas. Planta Daninha, v. 19, p. 359-366, 2001.

CUNNINGHAM, S. D.; ANDERSON, T. A.; SCHWAB, A. P. Phytoremediation of soils contaminated with organic pollutants. Adv. Agron., v. 56, p. 55-114, 1996.

DAL PICCOLO, C. R.; CHRISTOFFOLETI, P. J. Efeito residual de herbicidas utilizados na cultura da cana-deaçúcar sobre a Crotalária juncea L. em rotação. Saccharum, v. 8, p. $34-38,1985$.

EMMERICH, W. E. et al. Fate and effectiveness of tebuthiuron applied to a rangeland watershed. J. Environ. Qual., v. 13, p. 382-386, 1984.

HOAGLAND, R. E.; ZABLOTOWICZ, R. M.; LOCKE, M. A. An integrated phytoremediaton strategy for chloracetamide herbicides in soil. In: PHYTOREMEDIATION OF SOIL AND WATER CONTAMINANTS, 1997, Washington. Symposium Series... Washington, DC: American Chemical Society, 1997. p. $92-105$.

KRUGER, E. L. et al. Atrazine degradation in pesticidecontaminated soils: phytoremediation potential. In: PHYTOREMEDIATION OF SOIL AND WATER CONTAMINANTS, 1997, Washington. Symposium Series... Washington, DC: American Chemical Society, 1997. p. 54-64.

LORENZI, H. Manual de identificação e de controle de plantas daninhas: plantio direto e convencional. Nova Odessa: Plantarum, 20001. 339 p.

MACEK, T.; MACKOVÁ, M.; KÁŠ, J. Exploitation of plants for the removal of organics in environmental remediation. Biotechnol. Adv., v. 18, p. 23-34, 2000.

MEYER, R. E.; BOVEY, R. W. Tebuthiuron formulation and placement effects on response of woody plants and soil residue. Weed Sci., v. 36, p. 373-378, 1988.

RODRIGUES, B. N.; ALMEIDA, F. S. Guia de herbicidas. 4.ed. Londrina: 1998. 648 p.

SCRAMIN, S.; SKORUPA, L. A.; MELO, I. S. Utilização de plantas na remediação de solos contaminados por herbicidas - levantamento da flora existente em áreas de cultivo de cana-de-açúcar. In: MELO, I. S.; SILVA, C. M. M. S.; SCRAMIN, S.; SPESSOTO, A. Biodegradação. Jaguariúna: EMBRAPA Meio Ambiente, 2001. p. 369-371.

SILVA, J. F.; BUENO, C. R. Tolerância de legunimosas de cobertura do solo a herbicidas. I. In: CONGRESSO BRASILEIRO DA CIÊNCIA DAS PLANTAS DANINHAS, 22., 2000, Foz do Iguaçu. Resumos... Foz do Iguaçu: SBCPD, 2000a. p. 375.

SILVA, J. F.; BUENO, C. R. Tolerância de leguminosas de cobertura do solo a herbicidas. II. In: CONGRESSO BRASILEIRO DA CIÊNCIA DAS PLANTAS DANINHAS, 22., 2000, Foz do Iguaçu. Resumos... Foz do Iguaçu: SBCPD, 2000b. p. 376. 